Márton Varju*

\title{
RESPONSIBLE RESEARCH AND INNOVATION (RRI) IN HUNGARY: A WESTERN MODEL, AN EASTERN ILLIBERAL REGIME, AND A CASE OF DEFERRED INSTITUTIONAL ADAPTATION
}

\begin{abstract}
Responsible research and innovation (RRI) is a mode of research, development and innovation (RDI) governance which has proliferated primarily in European states with a tradition and/or culture of participatory and deliberative technology governance. It assumes the existence of open, transparent and accessible policy-making processes, and a culture of responsibility and accountability in government and in the private domain. In Hungary, where RDI is supposed to be the key to economic competitiveness, RRI has never taken root. Examining the regulation of the Hungarian RDI system, it becomes clear that there is a significant degree of institutional incompatibility with the solutions promoted by RRI. More significantly, the contemporary system of government and administration and the prevailing model of policy-making and governance prevent or exclude deliberately the implementation of RRI.
\end{abstract}

Key words: RRI, responsible research and innovation, research and innovation systems, institutional adaptation, illiberalism, neo-Weberian state, Hungary.

\section{INTRODUCTION}

Responsible research and innovation (hereinafter: RRI) has become a central concept in Europe in the governance and regulation of research, development and innovation (hereinafter: RDI) systems and RDI activities.

Senior Research Fellow, Eötvös Lóránd Research Institutes (ELKH), Centre for Social Sciences, Budapest, Researcher, Center for Ethics and Law in Biomedicine, Central European University, Budapest; e-mail: varju.marton@tk.hu. The research leading to this publication was supported by the Bolyai János Scholarship of the Hungarian Academy of Sciences. 
It is based on the ideas of transparency, participation, deliberation and engagement in the operation of RDI systems and their institutions, which have been applied as normative requirements and/or expectations in certain states concerning the conduct of government, business, scientific and societal actors in RDI. As a mode of governance and regulation, RRI assumes a partially horizontal - as opposed to a strictly hierarchical operation of the RDI system and RDI processes, and it calls for mutual cooperation and a commitment to the mutual understanding of different interests and needs among the different actors. Based on these characteristics, the successful adoption of RRI in national RDI systems presumes an operation of governance and administration which is deliberative and seeks consensus, where societal opinions and concerns are as relevant as the political and the economic interest, and where it is possible to measure the societal, moral and other costs and risks of human and corporate conduct against their expected economic and other policy benefits. In other states, for instance where consensus-building on significant societal issues is deliberately suppressed in politics, where efficiency and efficacy are paramount interests in governance and regulation, and where the perceived economic benefits of human and corporate activities have pre-eminence over potential societal, moral and other concerns, the institutional adaptation required by RRI may only be sporadic, or may be missing completely. RRI, which can change or undermine prevailing power structures, may in fact be undesirable in certain political systems.

In this article, we will examine the potential reasons for RRI never gaining substantial ground in the governance and regulation of the Hungarian RDI system. In particular, we aim to identify the institutional and other incompatibilities which have prevented the institutional adaptation promoted by RRI. First, we introduce the concept of RRI, as well as the specific requirements it may impose on national RDI systems and their institutions. For a better understanding of the required institutional changes, we scrutinize a few particularly revealing institutional best practices of RRI within Europe. Next, we provide an overview scrutiny of the regulation of the Hungarian RDI system with a focus on its main objectives and institutions. Our aim is to define its central characteristics as a system of RDI governance and administration. This prepares our final analysis of institutional incompatibilities between RRI and the system of government and administration in contemporary Hungary. We conclude by highlighting the many obstacles which may be responsible for deferring the implementation of RRI in Hungary. 


\section{RRI ANd Its Requirements For RDI Regulation AND GOVERNANCE}

RRI stands for a normatively determined mode $^{1}-$ more realistically, modes - for the organization, steering and governance of RDI systems and activities. ${ }^{2}$ It requires - minimally - the introduction of institutional solutions which ensure the participation of the relevant actors and stakeholders in RDI processes, and in the RDI system at large, as well as their actual influence on RDI policies, programs and other frameworks. The preferred institutional solutions enable the introduction and the operation of open, transparent, cooperative and deliberative modes of RDI governance, ${ }^{3}$ where RDI activities are constantly informed of and are harmonized with the social, moral, cultural, environmental, sustainability and other expectations and demands established against them. ${ }^{4}$ National RDI systems, which adhere to RRI, are thus open, less or non-hierarchical, and are organized and governed in a manner which fosters participation, deliberation, reflexivity and responsiveness. As outcomes, such modes of governance of the RDI system are expected to ensure that RDI activities lead to the realization of the societal results which have been identified in the RRI process as beneficial, and that RDI activities respond to the changes occurring in their societal, political, moral and other environment. ${ }^{5}$ RRI aims to address, organize and govern RDI activities, as well as the related industrial production processes, having regard to their social and moral acceptability, sustainability and necessity - in general, their social desirability, and thus to counterbalance the traditional, predominantly economic and industrial policy objectives of RDI systems. ${ }^{6}$ Ultimately,

1 RRI can denote a process and the outcomes (the "product") generated in that process, Schomberg, R. von, A Vision of Responsible Research and Innovation, in: Owen, R., Heintz, M., Bessant, J., (eds.), 2013, Responsible Innovation, London, Wiley, pp. 65-66.

2 For an overview of the conceptual matrix of RRI, see Ribeiro, B. et al., 2017, A Mobilising Concept? Unpacking Academic Representations of Responsible Research and Innovation, Science and Engineering Ethics, Vol. 23, No. 1, p. 87.

3 Schomberg, R. von, Prospects for Technology Assessment in a Framework of Responsible Research and Innovation, in: Dusseldorp, M., Beecroft, R., (eds.), 2011, Technikfolgen abschätzen lehren: Bildungspotenziale transdisziplinärer Methoden, Wiesbaden, Vs Verlag, p. 48; Schomberg, R. von, 2013, p. 64.

$4 \quad$ Ibid.

5 Ibid.

6 Schomberg, R. von, 2011, p. 48; Schomberg, R. von, 2013, p. 64; Blok, V., Lemmens, P., The Emerging Concept of Responsible Innovation. Three Reasons Why It Is Questionable and Calls for a Radical Transformation of the Concept of Innovation, in: Koops, B.-J. et al., (eds.), 2017, Responsible Innovation 2, Cham, Springer, pp. 19-35; Gianni, R. et al., Introduction: RRI: A Critical-constructive Approach, in: Gianni, 
RRI wants to make sure that society at large is given opportunities to determine its own technological future. ${ }^{7}$

In order to ensure that it fulfils its central objective of steering RDI towards socially desirable results, ${ }^{8}$ RRI imposes a number of qualitative requirements on RDI processes and systems. These requirements are anticipation, reflexivity and responsiveness, inclusiveness, deliberation, and the reconciliation of interests. ${ }^{9}$ As is apparent, some of the requirements address the mode of RDI organization and governance, others concern the substance of RDI policy and programs. The requirements correspond with the understanding of the RDI system and RDI processes - as promoted by the concept of RRI - that they should be able to observe and integrate the relevant social, moral and other considerations, should be able adapt to the demands which arise from their social, cultural, moral and other environment, and should be open for modification or readjustment when such developments are made necessary by these changes. ${ }^{10}$ Generally, the RDI system is expected to co-evolve with RRI and its outcomes. In practice, this may entail that RDI actors take part in developing the values and other considerations which will later be implemented in RDI processes, and participate in the continuous process of their reassessment and redesigning having regard to the societal, moral, environmental and other factors identified by RRI. ${ }^{11}$ In addition to ensuring the participation in and the impact on the RDI system of the relevant stakeholders and societal actors, the implementation of RRI requires the creation of actual

R. et al., (eds.), 2019, Responsible Research and Innovation: From Concepts to Practices, Abingdon, Routledge, pp. 1-7; Owen, R. et al., 2012, Responsible Research and Innovation: From Science in Society to Science for Society, with Society, Science and Public Policy, Vol. 39, No. 6, p. 754.

$7 \quad$ RRI is based on the joint commitment of the relevant partners to ensure by means of a responsible stewardship of RDI activities a future for humankind, Owen, R. et al., A Framework for Responsible Innovation, in: Owen, R. et al., (eds.), 2013, Responsible Innovation: Managing the Responsible Emergence of Science and Innovation in Society, London, Wiley, p. 36.

8 Stahl, B. C. et al., Responsible Research and Innovation in Information and Communication Technology: Identifying and Engaging with the Ethical Implications of ICTs, in: Owen, R. et al., (eds.), 2013, p. 214; Gianni, R., 2019, p. 8.

9 Owen, R. et al., 2013, p. 29; Stilgoe, J. et al., 2013, Developing a Framework for Responsible Innovation, Research Policy, Vol. 42, No. 9, p. 1568. As a precondition, the relevant actors and their relationship with each other must be characterized by mutual responsiveness, as well as by mutual commitment towards delivering a socially responsible and integrated RDI policy, see Schomberg, R. von, 2013.

10 See, in this regard, Owen, R. et al., 2012, p. 755.

11 Practically, it involves a continuous process of co-creating the frameworks of responsibility and accountability in RDI. 
responsibility frameworks, as well as frameworks for ensuring accountability for the societal, moral, environmental effects and risks of RDI. ${ }^{12}$

The implementation of the earlier mentioned RRI requirements requires that $\mathrm{RDI}$ processes, as well as the general RDI policy process are operated in a cyclical manner. Their cyclicality entails, in particular, that there are regular opportunities for ex post evaluation and for making the corrections made necessary by the evaluation results. Such organization and operation of RDI processes is essential when the aim is to ensure that the results of the gradually developing consensus over the societal, moral, environmental and other impacts of specific technologies can be integrated into RDI. Radical changes in technologies, or their (expected) radical - potentially disruptive - effects also require cyclicality in the operation of RDI systems. As another key solution for the implementation of the RRI requirements, RDI processes and the RDI policy process itself must provide robust and visible points of entry for the relevant stakeholders and other interested parties. These points of entry should preferably be connected to institutional frameworks which enable active and meaningful participation in and influence over RDI processes. As raised previously, the participation of societal and other actors in the RDI system should not be a mere formality; it should enable outcomes which guarantee that RDI outputs are genuinely desirable and necessary for society. The preferred institutional solutions include the ethical review of RDI activities and outputs (technologies), RDI - and technology-assessment frameworks, institutionalized public consultation, public engagement, and societal and/or industrial dialogue processes, or the introduction and the enforcement of codes of ethics for RDI and for industrial production, or of other RDI management, incentive or steering tools. ${ }^{13}$

In general, RRI wants to make sure that in a particular area of governance and regulation, where outputs have a direct impact on societal well-being and on the possible future of society, responsibility for present and future actions by all public and private actors is embedded in the system. Furthermore, it aims to ensure that the institutional framework of governance operates under a strict requirement of openness, transparency and accountability. ${ }^{14}$ Also, it expects that political and other forms of hierarchical control are relinquished to some extent with the purpose of ensuring that a broad range of (plural) societal, moral and other

12 See Zwart, H. et al., 2014, Adapt or Perish? Assessing the Recent Shift in the European Research Funding Arena from 'ELSA' to 'RRI', Life Sciences, Society and Policy, Vol. 10, No. 11, pp. 1-19.

13 That would steer RDI and industrial production towards socially desirable impacts.

14 And self-reflection. 
interests, needs and expectations can determine policies and, beyond policies, actual human activities, such as industrial innovation and industrial production. As further components of the model promoted by RRI, an open deliberative process is used to determine priorities, funding and desired outputs for RDI. Public and private actors are driven - for instance, as a result of a consensus reached among them - to accommodate and implement values, considerations and expectations which may not necessarily be theirs. Arguably, RRI may have the practical consequence of separating an area of administration and governance, and with that an area of economic and industrial production, from the prevailing power and interest structures in the given polity. ${ }^{15}$ It enables control over technologies and over the technological future by actors and by value-based and other considerations, which would normally be excluded from the political or the policy-making process. Based on these characteristics, the institutional adaptation which may be necessary for the implementation of RRI may face considerable obstacles in particular systems of governance and administration, or may be deliberately resisted by national politics. Institutional incompatibilities with a national system, which lacks a culture of non-hierarchical, participatory decision-making and (deliberative) governance, may in fact be the greatest obstacle to the (successful) adoption of RRI.

There is plenty of evidence that the emergence of RRI and its manifestation in concrete institutions and processes have been uneven among European states. ${ }^{16}$ In States with a long-term tradition of deliberating the societal relevance and impact of science and technology, as well as the responsibility of public and private RDI actors, and where RDI governance and administration have traditionally engaged with these issues, the implementation of RRI in RDI processes and in the RDI system has been wide-spread and substantive. In others, where RDI governance and regulation have been regarded as an exclusive task of the state, and where RDI has been administered - it being responsible for economic growth, competitiveness and employment - as part of national economic and/or industrial policy, the presence and impact of RRI have been more marginal.

15 As another problem issue, which may make the institutional implementation of RRI a rather sensitive question in certain states, RRI itself creates a power structure and has an evident power function. Afterall, RRI determines which actors, following which priorities and interests and in what way bear influence on the development and the use of certain technologies.

16 See Pearson, J., Ever Deeper Research and Innovation Governance? Assessing the Uptake of RRI in Member States' Research and Innovation Programmes, in: Gianni, R. et al., (eds.), 2019, Responsible Research and Innovation: From Concepts to Practices, Abingdon, Routledge, pp. 99-128. 
The level and/or sophistication of economic and societal development in a state - in other words, whether the national economy can financially and socially afford to take account of the non-economic, social, moral, environmental, sustainability concerns of technological developments seem to play a key role in the local adoption of RRI. Furthermore, local traditions of governance and administration, in particular the prevailing culture of legal regulation may prevent a possible adoption of RRI models and practices. A tradition of regulating public policies and their institutions in legislation by means of the rather limited solution of enumerating state and other public tasks, and of establishing formal institutional responsibilities for the implementation of those tasks, seems to be incompatible with the approach promoted by RRI, and may prevent the latter's uptake in regulation and governance.

\section{Best RRI Institutional Practices}

The following selective overview of national best practices demonstrate what may be preferred institutional solutions for the implementation of RRI. Not all of the discussed best practices are RRI solutions or tools per se, nor do they represent ideal or perfect responses to the requirements promoted by RRI. Nevertheless, they reveal an orientation or approach in national RDI systems which could be indicative as to what may be missing from other, more hierarchical, less transparent, and less open and accessible national RDI frameworks.

\subsection{THE DUTCH RESEARCH COUNCIL'S RESPONSIBLE INNOVATION PROGRAM}

The responsible innovation program and platform ${ }^{17}$ of the Dutch Research Council (the NWO) is perhaps the most commonly cited example of the institutional implementation of RRI in national policy. The platform is linked to the program of the Research Council which funds responsible innovation (research) projects. The platform serves the purpose of communicating the results of these projects and fostering the application of project results in the domain of RDI. It also serves as the basis of the responsible innovation network established by the Research Council, in particular by enabling the exchange of information among the participating researchers, civil society organizations, national authorities, and business representatives. The commitment of the council to promoting responsible research follows two main rationales: activities and research in RRI are

17 https://www.nwo-mvi.nl/. MVI: Platform voor Maatschappelijk verantwoord innoveren. 
guaranteed to receive government (research) funding and RRI priorities are given effect in the work of the council in organizing RDI activities. Since 2012, every responsible innovation (research) project financed by the Research Council must be implemented in cooperation with the representatives of the relevant strategic sectors of the Dutch economy. This change had a twofold objective: to ensure the responsible exploitation of socially trusted research results in the national economy, and to steer the RDI process in a manner which enables that the societal and ethical aspects of science and technology can be addressed and integrated on time, before the emergence of higher moral and societal costs or risks.

As a funding priority, the council prefers multidisciplinary responsible innovation (research) projects which aim to address highly relevant and complex societal challenges, as well as the potential scientific and technological responses to these challenges. The financed projects are expected to explore and identify the societal aspects of the relevant technologies early in the process of technological development, and to ensure, as a result, the development of the technology in its later stages will be able to internalize ${ }^{18}$ the social issues and risks revealed. ${ }^{19}$ The projects should lead to RDI outputs which will be accepted by society, and will not cause societal failures and/or significant ex post adjustment or correction costs for society. As a key institutional solution, every responsible innovation project financed by the council needs to establish a so-called valorization body. This body comprises of representatives of interested (government, business, public interest) actors. Its task is to identify how the technology or other RDI outputs will influence the practices of the relevant actors, and to make sure that this particular information is internalized in the RDI process. ${ }^{20}$ As a further role, the body can act as an intermediary between the RDI process and the industrial production and other processes, where the application and/or exploitation of results may take place. The

18 The (technological) output of the research or innovation process must reflect on/ internalize the relevant societal values (e.g., democracy, security, freedom, responsibility, justice, health, sustainability), and must internalize the available knowledge on the relevant societal processes, the expected behavior of human users, and on the social, political and moral aspects of the technology. In case of a conflict between the relevant societal values, the technology in question is expected to enable the resolution of that conflict, or to create a balance between the competing values and other considerations.

19 The Research Council prefers to fund projects which from their kick-off and/or during their entire lifetime address the societal (in particular, the legal, ethical, philosophical, economic, sociological, psychological, behavioral science) aspects of the given technology, as well as the impacts of that technology on individuals and their communities.

20 Which then ensures that the relevant RDI outputs reflect on the practices of the social, economic, political and other areas represented in the body. 
exchange of information within the valorization body is expected to be mutual and to go in both directions. ${ }^{21}$

\subsection{THE GERMAN COMMUNITY SCIENCE FRAMEWORK}

The German so-called Citizen Science Platform (Bürger schaffen Wissen - GEWISS) ${ }^{22}$ presents another important example of the institutional implementation of RRI. This is the central platform for community science in German. It is operated, with the financial support of the federal ministry for education and research, by the Berlin Science Museum and by Wissenschaft im Dialog (WiD) $\mathrm{GmbH} .{ }^{23}$ Its central task is to represent, connect and support - as an umbrella organization - the initiatives for citizen/community science in Germany. Its central objective is to make such projects more efficient in general, and more effective in influencing RDI activities, as well as the public discourse on science and technology. According to the definition laid down in the Green Paper prepared by GEWISS, ${ }^{24}$ community science refers to the active participation of citizens in the different phases of RDI activities. It also includes activities which ensure active mutual learning and experience sharing among representatives of the scientific research community and society at large in RDI.

Community science can involve different activities, such as the joint and mutual determination of research questions and research design, or also the direct participation of citizens in research projects, for instance in the collection of data or in the communication of research results. ${ }^{25}$ As set out in the Green Paper, the main aim of these activities is to develop knowledge about the social, political and economic importance of individual research projects, and about their potential applications in society,

21 Business and other actors can influence the design and the implementation of national RDI policy, for instance by determining research priorities having regard to both business and social needs. The research community receives more direct information concerning the expectations of businesses, the government and society, and can also explore which of their outputs may be more successful or competitive because it is socially more acceptable and/or trusted.

22 https://www.buergerschaffenwissen.de/en.

23 https://www.wissenschaft-im-dialog.de/en. Originally, it was established as a science communications organization. Now, its main task is the organization of societal dialogues and other social engagement activities in the context of scientific and technological research and development.

24 https://www.buergerschaffenwissen.de/sites/default/files/grid/2017/11/21/gewiss_cs_ strategy_englisch_0.pdf.

25 And in the dissemination of scientific and technological knowledge in society, in reinforcing the linkage between science and society, and in fostering the understanding of scientific advances and their risks. 
in politics and in the economy. Ultimately, it is expected that community science projects will make the research sector more open and accommodating, especially towards the social implications of scientific and technological development, and will enable the research sector to internalize the latter issues in its operation. Furthermore, community science will empower citizens as users of RDI outputs by enabling them to represent more effectively their shared interests against those of the research sector, and to force RDI actors to cooperate with current and future users. Citizens may also compel RDI actors to work on technological responses and solutions which can address what citizens regard as current or prospective social, political, economic, environmental and other problems at local, regional, national and international level.

\subsection{THE GERMAN HIGH TECHNOLOGY STRATEGY}

The German Strategy for High Technology $2025^{26}$ explicitly pursues the aim of fostering and supporting RDI activities which will benefit the people directly. It conceptualizes technological development and innovation as processes which are positioned at the cross-roads of politics, society, the economy, and science. The central priority of the strategy is to ensure the development of technologies ${ }^{27}$ which enable Germany to address the grand societal, environmental and economic challenges of the future. The priority point of fostering innovation for the direct benefit of the people entails the creation of innovation which is useful for the people, is able to satisfy their current and future needs, and is capable of helping people in their everyday lives. As a related priority, the strategy envisions cooperation between researchers, experts and technology users (citizens), who have the knowledge which is necessary to develop and/or to influence or steer the development of disruptive, socially highly useful technologies, and who will be able to use these technologies adequately. Correspondingly, the strategy's third priority conceives processes of technological development and innovation as collaborative frameworks which are based on the sharing of ideas. This presumes active cooperation between the relevant government, business, industrial, scientific, and societal actors, as well as an adaptive implementation of technological development and innovation processes. The latter notion refers to the

26 https://www.hightech-strategie.de/en/index.html and https://www.bmbf.de/upload_ filestore/pub/Research_and_innovation_that_benefit_the_people.pdf.

27 Its concept of innovation covers both technological and social innovation which are necessary to address these challenges. 
idea that RDI processes must enable the adjusting of the relevant RDI activities to the outcomes produced in the regular processes of societal and other dialogues, as well as in the regularly organized technological and societal foresighting assessments. ${ }^{28}$

The strategy emphasizes that its implementation must involve procedures for public engagement and societal dialogue. Regular consultations in organized forms with interested citizens, such as the organization of so-called Future Forums should also form part of implementation. The dedicated public engagement program of the strategy aims to achieve two major objectives. First, it aims to prepare society for the secure and effective application of new (digital) technologies in everyday life. Second, it wants to make sure that the relevant societal needs and expectations are communicated to RDI actors, and that these actors have sufficient knowledge of the social processes and/or circumstances in which the use and the eventual proliferation of the new technology is expected. The previously mentioned German community science framework is given a specific role in this regard. The strategy makes an explicit commitment to involving citizens actively in RDI processes, in particular in the domains of artificial intelligence, big data and human-technology interactions. ${ }^{29}$ As a related implementation commitment, the strategy volunteers to integrate into RDI the relevant results of the humanities and the social sciences, in particular in the domains of ethics, law and gender studies. According to the strategy, without this multidisciplinary knowledge RDI activities will be prevented from creating scientific and technological outputs which will be useful for the people in their everyday lives and which will not lead to excessive risks or costs for society and the individual. ${ }^{30}$ Ultimately, the integration of non-technological knowledge into RDI is expected to ensure the responsible performance of RDI activities.

28 The High Technology Expert Commission is one of the major forums for collaborative work between the scientific, industrial-technological and the non-governmental sectors.

29 The dedicated community platforms already in place, such as the Plattform Lernende Systeme, or the Competence Centre Public IT will play an important role in this regard. The strategy also mentions the so-called Science Years program which provides public opportunities for dialogues between politics, society and science.

30 This assumes that based on this knowledge a critical, reflective and future-oriented assessment of technological and the related societal changes will take place. Furthermore, the grand societal challenges, as well as the political and social problems - solving which requires novel technologies - may only be identified and explored with the help of the humanities and the social sciences. These disciplines can also contribute substantively to identifying the values and the expectations which need to prevail in the society of the future. 


\subsection{THE STRATEGIC FRAMEWORK FOR SCIENTIFIC RESEARCH IN FRANCE}

The 2020 French National Research Strategy, ${ }^{31}$ which was developed after two and a half years of public consultation, declares that the objective of scientific research includes the creation of novel scientific knowledge, as well as fostering economic growth and responding to contemporary and future societal and environmental problems. According to this integrative concept of scientific research, RDI activities must be carried out in the framework of "cooperative work" between the relevant scientific, business, government, and societal actors. The related resolution No. 926 of the National Assembly 32 defines the function of scientific research as "enriching the culture of French citizens who want to understand the world". As a specific task in this regard, the resolution motioned the government to support and develop scientific education and training, as well as education in the philosophy of science, to support science communication activities, and to foster active citizen involvement in debating the relevant questions and dilemmas of RDI activities, in particular those relating to the risks and hazards of technological development. The national strategy of "Science, technology and industrial culture" 33 shares this cultural definition of scientific research and technological development. It declares that science and scientific research forms part of the culture of citizens. This conceptualization thus assumes that citizens have access to information on questions of science and technology, and are offered opportunities to reflect on them. In a similar vein, citizens must be afforded means to participate in the societal and ethical debates concerning the benefits, the uses and the risks of science and technology.

\subsection{THE PUBLIC ENGAGEMENT ACTIVITIES OF THE UK RESEARCH AND INNOVATION AGENCY}

The UK Research and Innovation Agency is entrusted in legislation ${ }^{34}$ with the task of ensuring the collection, the development, the dissemination, and the sharing of information and knowledge on scientific research,

31 https://cache.media.enseignementsup-recherche.gouv.fr/file/Strategie_Recherche/26/9/strategie_nationale_recherche_397269.pdf.

32 http://www.assemblee-nationale.fr/14/ta/ta0926.asp (Résolution de l'Assemblée nationale sur les sciences et le progrès dans la République).

33 https://www.enseignementsup-recherche.gouv.fr/cid113974/la-strategie-nationale-de-culture-scientifique-technique-et-industrielle.html.

34 Higher Education and Research Act 2017, Section 93. 
technological development and scientific thinking. ${ }^{35}$ As a related task, it must foster the understanding of these three areas in society. The public engagement framework ${ }^{36}$ of the agency is based on the idea that the delivery of RDI activities, which have genuine societal benefits, are socially relevant, and can be trusted by users and by society at large, requires far-reaching societal dialogues and the effective participation of societal actors in RDI systems. ${ }^{37}$ Provided that they develop genuine connections with members of society, especially those who are traditionally underrepresented in the RDI domain, RDI actors have a genuine chance to improve the quality of their work and its expected positive impacts, and to make the outputs of their work more relevant for society. The flagship societal dialogue program of the agency, which is called Sciencewise, ${ }^{38}$ covers the entire RDI system in the UK and is used to inform a broad spectrum of government policies. The deliberative public dialogues organized within Sciencewise are commissioned by government bodies in the UK (ministries, government agencies, other government bodies, and government advisory bodies) with the purpose of ensuring and/or enhancing the social understanding and acceptance of their policies within the broader domain of RDI.

Sciencewise societal dialogues are expected to be representative of UK society. They are also expected to provide sufficient substantive information regarding opinions, needs, concerns, and expectations in society in connection with specific technologies or scientific developments. The public dialogues organized by Sciencewise must be able to produce results which can be applied directly in the RDI policy process. Currently, Sciencewise activities cover the four grand economic and societal challenges which were identified by government, as well as the specific area of genomics and gene editing. The UK government's expectations towards societal dialogues are summarized in the so-called Sciencewise guiding principles, which were developed in a collaborative process with the relevant social actors. ${ }^{39}$ The guiding principles follow the central idea that in

35 According to the statutory definition, the exchange of information facilitated by the agency must contribute to achieving an economic or social advantage in the UK or elsewhere.

36 https://www.ukri.org/public-engagement/research-council-partners-and-public-engagement-with-research/; https://www.ukri.org/files/per/ukri-vision-for-public-engagement-pdf/.

37 The development of RDI policy and the RDI funding system must also build on such public engagement commitments.

38 http://sciencewise.org.uk/.

39 http://sciencewise.org.uk/wp-content/uploads/2019/11/Guiding-Principles.pdf. The guiding principles are also available as best practice guidance for other societal dialogue initiatives. 
order to ensure that RDI is able to respond to the interests of society and the economy, the relevant societal, economic, environmental and other problems and challenges, as well as the potential responses given to them need to be determined in the framework of constructive dialogues based on equal participation opportunities for all concerned actors. ${ }^{40}$ Sciencewise has also developed its own general quality requirements for societal dialogues and a number of organizational principles. The former involves, for example, the requirement of equal opportunities of intervention by participants. The latter concerns principles, such as the guaranteed implementation of a "policy hook" or the obligation to integrate results into the policy process. Sciencewise follows a detailed set of quality requirements. ${ }^{41}$ Principally, societal dialogues must provide a genuine opportunity for influencing government policy, if necessary, by convincing government to depart from its preferred societal, ethical, policy and another position or viewpoint.

\section{The Hungarian RDI System}

The Hungarian RDI system is regulated in Act 2014:LXXVI on scientific research, development and innovation (hereinafter: Act on innovation). As a central objective of the system, the measure provides that the exploitation of RDI results and outputs in the national economy must become a reality, and this must contribute to economic development and growth in Hungary. ${ }^{42}$ As a related objective, it requires that the available "RDI supply" is harmonized with the demands and needs of economic operators in the national economy. The 2019 modification of the act, which was adopted with the declared aim of inducing a paradigmatic change in the politics and governance of science and innovation in Hungary, did not depart from the principally economic (economic and industrial policy) focus of the regulation of the RDI system. ${ }^{43}$ Furthermore, Act 2019:LXVIII ${ }^{44}$ continued the tradition of the 2014 measure of regulating - without

40 The concept of societal dialogue is defined as a process in which members of society are connected with representatives of the RDI sector and of the relevant government bodies with the purpose of debating issues and questions which can determine the future shaping of the relevant policies.

41 http://sciencewise.org.uk/wp-content/uploads/2018/09/Sciencewise-Quality-in-Public-Dialogue-August-2018.pdf.

42 The defense and security policy relevance of RDI was also acknowledged by the 2014 act.

43 The relevant government decision (Decision 1481/2018 (X. 4.)) ordered the reform of the RDI system with the purpose in increasing economic competitiveness.

44 On the amendment of the institutional and financial framework of the RDI system. 
offering a novel, societally more complex orientation for RDI activities the institutions and the organizational/administrative aspects of the Hungarian RDI system. The concept document prepared by the Ministry for Technology and Innovation in support of the 2019 amendment was heavily criticized by the Hungarian Academy of Sciences, which at that time was still among the central institutions of national research policy. ${ }^{45}$ The Academy of Sciences' material questioned the validity of the almost exclusively economic policy focus of the RDI system, and emphasized with reference to its own institutional task established in legislation that scientific research as carried out within that system must serve the "benefit of humankind, society, and the nation". 46 The document approached scientific research from a holistic perspective, and argued that besides economic development and growth research must also serve the interest of enabling governments and societies to give adequate responses to the grand problems and challenges of humankind. Additionally, scientific research must contribute to creating values of national importance, as well as to protecting national identity.

Admittedly, the framework established by the Act on innovation for the Hungarian RDI system is not completely ignorant of the potential societal and environmental relevance and impacts of RDI activities. The definition of exploitation of RDI outputs in 3 . $\$$, which priorities exploitation in the national economy for business purposes, recognizes the use of RDI results in the public interest, namely their utilization with the purpose of increasing the quality of life and the quality of public services, protecting the natural and the built environment, ensuring sustainable development in Hungary, and of improving the defense capacity and security situation of the country. However, these components of the RDI system do rather little in steering it away from its dominant economic and industrial policy objectives. ${ }^{47}$ Nor do they appear as specific obligations or requirements defined in the regulation of the institutions and procedures of the RDI

45 The concept of the Hungarian Academy of Sciences on the role of science in the reform of the national innovation system (2018), (https://mta.hu/data/dokumentumok/rendkivuli_kozgyules_20181206/20181206_MTA_RK_3_napirend_Az\%20 MTA\%20koncepcioja\%20a\%20tudomany\%20szerepere.pdf).

46 The 2019 modifying act recognized as a new task of the Academy the strengthening of links between researchers and society, which can be interpreted as an RRI-relevant legislative development.

47 The general regulatory priorities of the Act are the following: to guarantee the freedom of conducting scientific research and to provide its objective conditions, to ensure the competitiveness of the Hungarian economy and its ability to produce income (which assumes the creation of a knowledge-based society), to ensure economic growth which is capable of creating employment opportunities, to guarantee sustainable societal and economic development based on technological development 
system which require strict implementation by the RDI administration. As revealed by its preamble, the act follows and/or aims to implement a concept of RDI which places an emphasis on the economic benefits, as well as on the economic exploitability of RDI activities and their results. ${ }^{48}$ The other significant element of the act's RDI concept concerns the administration and financing of RDI activities by the State, which as expressed in the preamble must be efficient and reliable. ${ }^{49}$ There is no evidence in the act that Hungarian RDI policy and RDI activities would actually need to observe value-based or other societal considerations. ${ }^{50}$

The narrow remit of its RDI concept is clearly reflected in the act's RDI-specific regulatory priorities. They include the following:

- ensuring the predictability, stability, effectiveness, and transparency of RDI administration and financing by the State;

- linking processes of basic research, applied research, experimental development, and other technological development and innovation;

- ensuring the translation of RDI activities and their results in the Hungarian economy;

- supporting RDI-based economic operators and their competitiveness;

- the creation of workplaces which produce high added-value in the economy;

- improving the quality of research staff employed in the RDI sector;

- the creation of an economy based on knowledge and innovation, and ensuring as a result intelligent growth in Hungary.

The priorities laid down in $18 . \S$ for the financing (subsidizing) of RDI activities by the State confirm the focus of regulation on delivering direct economic results and prioritizing economic exploitability. There is, however, mention of the broader impact and usefulness of RDI. As a funding priority, RDI activities financed from public resources must produce genuinely new results, which can subsequently be exploited at a larger

and innovation, the production and the availability of advanced defense and security technologies.

48 The general principles laid down in $2 . \$$ of the Act define effectiveness, usefulness and exploitability as the main qualities of RDI activities.

49 The general principles laid down in 2 . $\$$ of the Act define RDI policy as a public policy, the implementation of which the responsibility of the State is limited to ensuring effective administration, financing and management.

50 The Act envisions the implementation of RDI activities as embedded in the national economy, and it relies in the implementation of RDI policy on the active participation of economic operators. 
scale in the national economy or in society, and which can contribute to the competitiveness of the Hungarian economy (or to the development of the digital ecosystem in Hungary). There is a specific emphasis on the necessity for the economic or industrial translation of RDI results, and on the development of RDI capacities which will lead to actual improvements in (industrial) productivity. The act makes it clear, nevertheless, that it expects results and outcomes from RDI which will contribute effectively and directly to the resolution of internationally and nationally relevant societal, environmental and economic problems. The financing priorities (24. $\S$ and $28 . \S$ ) of the corresponding financing tool - the National Research, Development and Innovation Fund - contain essentially the same considerations.

The RDI institutional framework regulated by the Act on innovation is centralized and hierarchical. The corresponding governance model is structured predominantly top-down. ${ }^{51}$ The rare horizontal or bottom-up structures are accessible for business actors only, and they thus enable the internalization of economic and business interests and considerations mainly. ${ }^{52}$ As mentioned previously, the central objective imposed on public institutions in the Hungarian RDI system is to ensure the efficient administration of the available public resources $(11 . \S(2)) .{ }^{53}$ The central public body in the RDI system is the National Research, Development and Innovation Agency. Its regulation in the act is restricted to its tasks, organization and administration. There is no evidence of institutional responsibilities, such as public engagement or the fostering of community science, which could be linked to RRI. The other major public institution is the National Research, Development and Innovation Fund. Its regulation does not include horizontal elements or other components which would open the RDI system towards societal actors, and which would ensure that RDI financing follows priorities other than the economic and industrial policy objectives regulated for the Hungarian RDI system. The operational and the management regulation of the Fund ${ }^{54}$ make reference to outreachand engagement-type activities, but these relate exclusively to the needs and interests formulated by business stakeholders.

51 The relevant provisions determine the tasks of the government and the tasks of other central government bodies $(4-5 . \$)$.

52 See, for instance, the National Council for Research Policy (Nemzeti Tudománypolitikai Tanács), which consists of State officials, a few senior scientists, and the representatives of large (partially State-owned) corporations.

53 Effectively, the act regulates three larger areas: the general administrative framework, the administration of State funding, and intellectual property rights. The second area is regulated in the most detailed manner.

54 380/2014. (XII. 31.) and 344/2019 (XII. 23.) Government regulations. 
In the relevant policy documents, the conceptualization of RDI has followed an approach which is similar to that of the Act on innovation. The 2013-2020 Hungarian RDI strategy ${ }^{55}$ prioritized the expected impact of RDI activities of enabling economic growth and enhancing the competitiveness of the national economy. Arguably, the National Research, Development and Innovation Agency, which was its author, had no other choice. Based on its evaluation of the RDI system, the agency identified certain fundamental hiatuses and problems which required immediate and substantive attention. This had the consequence that in the 2013-2020 period it was imperative for Hungarian RDI policy to focus on delivering on the most basic expectations towards RDI in a society. With this background and since its main task was to redesign and rebuild the RDI system in Hungary, the strategy addressed three implementation areas. These were the creation of competitive knowledge-bases, the establishment of effective knowledge- and technology-transfer systems, and guaranteeing the intensive exploitation of RDI results in the economy and in the public sector. It defined the main tasks of the State as increasing public expenditure on the RDI system, meeting in RDI and general administration and governance the expectations of the relevant corporate actors, and as establishing an "ecosystem" which supports RDI activities. RRI and similar initiatives, which had been circulating in Europe for some time, had no directly apparent influence on the strategy. ${ }^{56}$

The strategy also included a number of elements which from an RRI-perspective may bear some relevance. For example, the document mentioned the consumer as the final user of RDI results and outputs. It recommended that consumer needs and expectations should play a special role in the development of RDI policy and strategy in Hungary. It raised that RDI policy may deal with the consumer in two major ways: RDI results can provide responses to concrete consumer needs; RDI can create consumer needs which it may then satisfy. The strategy also discussed the importance of meeting societal demands and needs. However, this was not considered as a self-standing RDI objective. Instead, the document mentioned that RDI activities usually follow their own logic and they are largely ignorant of external needs, especially the demands of the market. It added that the uptake and exploitation of RDI results in the Hungarian economy and society has been rather limited, which needs to be changed. Arguably, the main concern of the strategy here was that the translation of RDI results into products and services has been inadequate in Hungary.

55 https://nkfih.gov.hu/hivatalrol/strategia-alkotas/nemzeti-kfi-strategia.

56 At the time of writing this article, there was no evidence of a new innovation strategy which would cover the period after 2020 . 
The strategy's analysis was not driven (directly) by some RRI-relevant objective or consideration. As part of its exploratory agenda, the strategy also took notice of the weaknesses of scientific-technological education in Hungary, in particular its failure to train future researchers.

In 2016, the strategy was followed up by a peer review report. ${ }^{57}$ It was commissioned by the National Research, Development and Innovation Agency, and was perhaps the most robust manifestation in Hungarian RDI governance of an idea of a responsible and responsive RDI sector. The report reviewed the entire strategy. Its assessments and critical recommendations revealed numerous hiatuses in the RDI system in Hungary. In our view, these provide evidence of institutional incompatibilities with and an obvious reluctance to implement the institutional adjustments promoted by RRI. For instance, the report recommended as its second policy message that the objectives and outputs of the Hungarian RDI system, which is dominated by economic and industrial policy priorities, as well as the timetable for their implementation need to be determined in the framework of a continuous dialogue among the relevant actors. This dialogue process should be organized with a view to achieving the ultimate objective of society being able to understand the RDI system. As a related recommendation, which admittedly concerned a specific segment of RDI governance, the report suggested that the relevant actors are provided opportunities to get involved in the operation of the agency. Such involvement opportunities should ensure that the agency discharges its responsibility of administering and financing RDI in a "structured" manner. It also recommended establishing a formal public participation platform at the agency. Furthermore, the agency was called to ensure the more effective handling of recommendations formulated by RDI actors and by its advisory bodies. The report raised that generally the agency must operate in a more transparent, more reliable and more responsible manner.

The report proposed that the participation of interested actors must be ensured in an RDI framework where RDI priorities and objectives are determined in a regular manner. In such a framework and in the corresponding process of developing and implementing specific RDI programs, it identified as the main participants the universities, the research institutes, the companies, the community of researchers, and the community of entrepreneurs. The report also suggested the establishing of an oversight committee for the National Research, Development and Innovation Agency. By involving the relevant governmental and non-governmental actors in this committee, the agency should be able to ensure

57 https://nkfih.gov.hu/hivatalrol/szakpolitika-strategia/kfi-helyzetelemzes. 
a more responsible operation. The advisory bodies of the agency, such as the National Scientific Advisory Body or the National Innovation Council should also be involved more effectively in its work. In particular, the recommendations or other policy advice from them should be implemented more visibly and effectively in Hungarian RDI policy. The report repeatedly criticized the closed institutional design of the RDI system. It raised that the system does not include a framework for public engagement and societal dialogue. As a result, policy priorities and directions are determined without a meaningful involvement by societal actors. Nor are representatives of adjacent, socially relevant areas of public policy involved in the agency's work. According to the report, this latter institutional hiatus had the consequence that RDI priorities are not harmonized with those of environmental, public health and other policies in Hungary, and that RDI priorities may not be integrated into the implementation of these policies. The report added that the societal, environmental and other problems and challenges, which RDI activities are supposed to address, were not determined in the framework of societal dialogues and in other reflective societal processes.

As a substantive policy criticism, which also found problems with the institutional design of the Hungarian RDI system, the report claimed that decision-making in RDI policy is not based on the collection, evaluation and application of the relevant facts and information. Basically, RDI priorities, objectives and the desired outputs were determined in Hungary in a top-down manner within the narrow remit of central government based on a limited range of evidence. ${ }^{58}$ The report pointed out that the objectives and priorities were picked in an incoherent manner, the choices and decisions supporting their selection lacked transparency, and their selection was not grounded on sufficient reasons. Furthermore, the system was put in place and was operated without systematic efforts to understand and evaluate - in collaboration with RDI actors - the challenges, the opportunities and the priorities of RDI in Hungary. The report also found that the RDI system was not equipped with an external evaluation framework which could compensate the limitations of the internal evaluation culture of the National Research, Development and Innovation Agency. The report was particularly critical of the excessively ambitious priorities and objectives set out in the Hungarian RDI strategy. It noted that this was unrealistic goal-setting meant that the RDI system, which can also be criticized for lacking an effective and coherent implementation framework, was practically prevented from realizing the objectives assigned to

58 The report mentioned specifically that the interests and concerns of actors outside of the narrower RDI governance framework are locked outside of the system. 
it by the policy-maker. As a specific issue, the report highlighted that the objectives and priorities of the RDI system had been determined without engaging with society. Nor had the relevant challenges and problems been selected based on the involvement of societal actors. Fundamentally, there is no evidence of government actors in $\mathrm{RDI}$ being inclined to open the RDI system towards society.

Curiously, the development of the 2014 national smart specialization strategy ${ }^{59}$ reveals a rather different image of the Hungarian RDI system. A possible cause of this difference is that smart specialization strategies are instruments of EU policy and should be developed according to common EU methodology. The Hungarian strategy was created as a planning basis for a national RDI strategy which relies on local assets and advantages. As a result, the RDI strategy prepared will be sustainable, can provide maximum social benefit, and will guarantee the highest returns. Industrial and economic policy priorities were given special relevance in the strategy, but also were issues of economic and social sustainability. The strategy envisioned an RDI system for Hungary in which technology and innovation have a reinforced societal acceptance and relevance, and where the institutional framework enables coordination among the relevant business, research and societal actors. The participation of the National Research, Development and Innovation Agency in this system will be based on the principle of "cooperative leadership". This entails that the agency maintains an active system of cooperation with the relevant actors. The strategy put forward the idea of the "co-management" of the RDI system with the participation of the State and the representatives of science, the economy and society. Such an RDI system can ensure that its outputs are available to everyone, and that the different expectations towards RDI, as well as the different RDI-relevant interest and needs can be successfully balanced against each other. Importantly, the strategy was negotiated and developed in a decentralized manner, following a bottom-up process, with the participation of local partners and resources. The process was characterized by rather extensive societal dialogues, as well as by efforts to coordinate among the different priorities of different policy areas.

\section{Assessment}

As revealed earlier, the RDI system in Hungary is based on an internally closed, hierarchical, top-down model of governance. These characteristics have developed despite the relative isolation of this field within government and administration and the direct influence of international

59 https://nkfih.gov.hu/hivatalrol/nemzeti-intelligens/nemzeti-intelligens. 
(European) examples. This is attested, in particular, in the conceptual framework of its regulation, as well as in the actual legal rules which remain content with setting out tasks for the institutions in the RDI system and assigning institutional responsibilities for the implementation of these tasks. The fundamental governing principles of the system prioritize the effectiveness and efficacity of its operation from the perspective of the predominantly economic and industrial policy priorities of RDI in Hungary. The same priorities follow from the (fiscal) policy expectations towards RDI funding from public resources. There is effectively no institutional evidence of a mode of governance and RDI administration which would enable actual societal participation in and influence on RDI processes and which would lead to a responsible and reflective internalization of the relevant societal, moral, environmental and other values, concerns or considerations. The social, moral or environmental necessity and desirability of RDI activities and RDI outputs are included neither in the priorities of the system, nor in the rules governing the conduct of institutional actors. In general terms, the RDI system seems to be influenced to such an extent by the state and the perceived imperatives of economic development in Hungary that other priorities and concerns relating to RDI and its broader environment are denied recognition. Shorter term economic needs practically prevent integrating issues concerning the technological future of Hungarian society into RDI policy.

These observations already make it evident that introducing institutional solutions for RRI in the Hungarian RDI system face limitations and/or obstacles that are peculiar to administration and governance in Hungary. ${ }^{60}$ The contrast between the institutional design of the RDI system in Hungary and that promoted by RRI is very sharp. As analyzed previously, RRI assumes - or rather demands - consensual/cooperative decision-making, or at least a balancing or the reconciliation of different interests and needs in a consensual manner. It is based on mutual openness and cooperation among the relevant public and private actors, including State bodies. RRI also presumes the transparency of RDI processes and the RDI policy process, as well as the unrestricted flow of information among State, business, societal, and other participants. The latter requires - as a matter of principle - the reduction of the information asymmetries which usually benefit State and business actors. Ultimately, the implementation of RRI may require the abandoning of positional and strategic advantages held by public and private actors, as well as separating

60 For an earlier, rather short and unstructured overview of the adoption of RRI in Hungarian policy-making, see Inzelt, A., Csonka, L., Responsible Research and Innovation in Hungary: Review of National Policies (ResAGoRa, 2013), (https://rritrends. res-agora.eu/uploads/10/RRI\%20in\%20Hungary\%201st\%20Report_final.pdf). 
$\mathrm{RDI}$ from the prevailing power structures in government, in the economy and in society. In a system of governance which lacks a culture and/or a commitment to participatory and deliberative decision-making in open, transparent and non-hierarchical processes, and where policy priorities and objectives are fixed unilaterally by government, the implementation of RRI would evidently be difficult, even practically impossible. The institutional adaptation required by RRI may also be prevented by a higher degree of incompatibility with the prevailing institutional culture, or be deliberately resisted by national politics as unacceptable in the prevailing political order.

According to the perhaps most influential analysis of contemporary, post-2010 Hungarian government and administration, Hungary has become a "plebiscitary leader democracy". ${ }^{11}$ This term was introduced to denote a highly centralized, top-down, hierarchical political system and system of government, in which the political leader is assumed to enjoy a practically unlimited political mandate. Other actors and participants e.g., societal actors - are forced into a passive political and societal role. As another important characteristic, the system rejects the plurality of viewpoints, interests and needs, ignores possibilities for consensus-building and deliberation, and institutions for popular (citizen) participation and involvement are used for the purpose of securing the legitimacy of the system (the leader), and not for informing and influencing substantive policy-making, and much less for making decisions concerning the (technological) future of society and its members. The free flow of information and equal opportunities of public participation among diverse private and public actors are contrary to the nature of the regime. Since politics and political voluntarism have been placed at the heart of government, and even of public administration, ${ }^{62}$ policy-making and policy implementation are prevented from fostering long-term horizontal relationships between public bodies, business operators, and research and societal actors which would subject influence and control over technologies and their use to non-political considerations, or to values and concerns that are not moderated or mediated by government politics. These system characteristics are fairly distant from those promoted by RRI.

Analyses of prevailing models of governance and policy-making in Hungary seem to confirm institutional incompatibility with RRI and question the prospect of RRI-driven institutional adaptation in the Hungarian

61 Körösényi, A. et al., 2020, The Orbán Regime: Plebiscitary Leader Democracy in the Making, Abingdon, Routledge.

62 Körösényi, A., 2019, The Theory and Practice of Plebiscitary Leadership: Weber and the Orbán Regime, East European Politics and Societies, Vol. 33, No. 2, p. 299. 
RDI system. According to these assessments, policy-making and governance in Hungary have experienced an extensive centralization, which was coupled with a radical concentration of discretionary decision-making powers at the highest level in government. ${ }^{63}$ Furthermore, there has been a deliberate elimination of internal and external checks and balances on the exercise of power by the centralized government. ${ }^{64}$ As a change affecting the substance of policy-making, effectiveness and efficiency have become the dominant - possibly exclusive - priorities for governance. ${ }^{65}$ In this local manifestation of what is supposed to be a neo-Weberian state, societal, moral, environmental and other interests, concerns or needs represented by non-state societal actors bear little influence or relevance, unless they are embraced by the state, nor do these societal actors have genuine access to and influence on policy-making and governance. The virtues of good governance, which latter concept has been recognized explicitly as a matter relevant for the implementation of the neo-Weberian model, such as participation, openness, transparency and accountability, have been implemented only sporadically, and have had an overall limited impact on the institutional structure and operation of public administration in Hungary and in Central and Eastern Europe at large. ${ }^{66}$

Having regard to the previously established realities of the Hungarian political system and the system of government and administration, the institutional adaptation promoted by RRI, which is fundamentally a Western concept and mode of technology governance, faces major and insurmountable obstacles in Hungary. These barriers and the incompatibility of RRI with government and administration in Hungary are not necessarily absolute. For instance, the Hungarian government can find the cyclical nature of governance - as it follows from RRI - attractive on grounds of effectiveness and efficiency. Also, national politics may find the negative environmental and societal impacts of technological change or development a relevant issue which can be exploited for political gains. Nevertheless, there are core aspects and institutional solutions of RRI the adoption of which in the Hungarian system of governance and administration

63 Hajnal, Gy., Illiberalism in the Making: Orbán-era Governance Reforms in the View of the Administrative Elite, in: Kovač, P., Gajduschek, Gy. (eds.), 2015, Contemporary Governance Models and Practices in Central and Eastern Europe, Bratislava, NISPAcee, p. 139.

64 Ibid.

65 Ibid., p. 140.

66 Gajduschek, Gy., Critical Notes on Four Major Theories of Public Administration as they Appear in Central and Eastern Europe, in: Kovač, P., Gajduschek, Gy. (eds.), 2015, Contemporary Governance Models and Practices in Central and Eastern Europe, Bratislava, NISPAcee, p. 167. 
is unlikely, which effectively excludes that RRI takes root in Hungary. These are, for example, meaningful societal consultations and dialogues sustained for the entire life-cycle of the given technology, or the equal consideration of interests and concerns raised by societal actors, RDI participants, business operators, and by the government. Arguably, the very essence of RRI, which is consensus-building among majority and minority viewpoints, and among a plurality of values and moral considerations, which are all treated as having equal weight and relevance, is incompatible with the current hyper-centralized nature of Hungarian government and administration. Such an approach is unlikely to be internalized by a politics which strives on societal conflict. The prospect that RRI may change or challenge the prevailing power structures and power relationships regarding technologies and their deployment can be perceived as a direct threat to the political regime. Also, Hungarian politics may be unwilling to take the risks which follow from the uncertainties in the direction RRI may define for technological development, or which arise from RRI keeping the desirable societal outputs of RDI undefined and alterable.

As an alternative explanation, the cause for any national government and administration being reluctant to make the institutional and other adjustments necessary for the implementation of RRI may be sought in the perceived lack of effectiveness of RRI tools, or in a skeptical assessment of the actual, implementable benefits of RRI for the governance and administration of RDI. ${ }^{67}$ RRI results, or the actual capabilities of RRI solutions, for instance, to operationalize responsibility in the RDI context, can indeed appear as rather uncertain, imprecise, or changeable from the perspective of a responsible RDI governance actor. ${ }^{68}$ As another problem with RRI, its focus on the "grand problems" of humankind, which are highly complex issues and are likely to attract similarly complex societal, moral, environmental and other considerations, may prevent the identification of values, concerns, needs, and other outputs that can be sufficiently effectively implemented in the RDI system. In addition, the complexity of these considerations may exclude their effective reconciliation with each other and may thus prevent consensus-building among the relevant actors. Considering that the economic and industrial policy benefits of RDI can be sufficiently well-defined and be well-anchored in the RDI system, public and private RDI actors may be reluctant to recognize and internalize the potentially broad and loosely defined - possibly inaccessibly complex - societal, moral, environmental and other considerations

67 The several hiatuses of the concept of RRI may themselves prevent its actual, effective and successful implementation. See Blok, V., 2017. See also Ribeiro, B., 2017.

Owen, R. et al., 2012, p. 756. 
and expectations presented by RRI. It may also be uncertain whether the societal and moral values identified by RRI can be implemented in a meaningful way in the process of technology design or in actual processes of industrial production. ${ }^{69}$ These are highly relevant problems with the implementation of RRI. However, considering the state of the regulation and administration of the Hungarian RDI system, as well as the realities of its political and governance environment, it is unlikely that they played a significant role in deferring the adoption of RRI in Hungary.

\section{Conclusion}

In this article, we introduced RRI as a mode of technology and RDI governance which places emphasis on the societal, moral, environment and other concerns, risks and expectations of technological development and change. It promotes an open, accessible and transparent governance of the RDI system which is based on participatory and deliberative decision-making capable of securing the influence of societal and other relevant actors and their interests, values and needs on RDI policy and RDI processes. Although it is a genuinely European concept and has found its way into EU technology and RDI policy frameworks, RRI has avoided implementation in the Hungarian RDI system. The predominantly economic policy-oriented objectives and priorities of RDI in Hungary, as well as its institutional framework have practically nothing in common with the objectives and approach promoted by RRI. The RDI system pursues priorities and objectives which seem to follow from the long-prevailing state of economic and social development in Hungary. This latter circumstance may in fact explain why RRI has not gained implementation. As a more forceful explanation, the contemporary system of government and administration in Hungary, as well as the prevailing model of policy-making and governance seem to be fundamentally incompatible with RRI, or exclude deliberately its implementation. In this age of excessive centralization and politicization, bottom-up modes of socially driven governance on matters as crucial as technology and technological development have hardly any viability in Hungary.

69 RRI was developed in the context of traditional RDI carried out by public research institutions. Thus, it is far from certain that it can be implemented in other RDI settings, such as systems for commercially driven industrial innovation and production. For instance, RRI assumes a willingness to cooperate and to reach a consensus in environments, which are in fact characterized by intensive competition and a deep division of interests. 


\section{BIBLIOGRAPHY}

1. Blok, V., Lemmens, P., The Emerging Concept of Responsible Innovation. Three Reasons Why It Is Questionable and Calls for a Radical Transformation of the Concept of Innovation, in: Koops, B.-J. et al., (eds.), 2017, Responsible Innovation 2, Cham, Springer.

2. Gajduschek, Gy., Critical Notes on Four Major Theories of Public Administration as They Appear in Central and Eastern Europe, in: Kovač, P., Gajduschek, Gy., (eds.), 2015, Contemporary Governance Models and Practices in Central and Eastern Europe, Bratislava, NISPAcee.

3. Gianni, R. et al., Introduction: RRI: A Critical-constructive Approach, in: Gianni, R. et al., (eds.), 2019, Responsible Research and Innovation: From Concepts to Practices, Abingdon, Routledge.

4. Hajnal, Gy., Illiberalism in the Making: Orbán-era Governance Reforms in the View of the Administrative Elite, in: Kovač, P., Gajduschek, Gy., (eds.), 2015, Contemporary Governance Models and Practices in Central and Eastern Europe, Bratislava, NISPAcee.

5. Körösényi, A., 2019, The Theory and Practice of Plebiscitary Leadership: Weber and the Orbán Regime, East European Politics and Societies, Vol. 33, No. 2.

6. Körösényi, A. et al., 2020, The Orbán Regime: Plebiscitary Leader Democracy in the Making, Abingdon, Routledge.

7. Owen, R. et al., 2012, Responsible Research and Innovation: From Science in Society to Science for Society, with Society, Science and Public Policy, Vol. 39, No. 6.

8. Owen, R. et al., A Framework for Responsible Innovation, in: Owen, R. et al., (eds.), 2013, Responsible Innovation: Managing the Responsible Emergence of Science and Innovation in Society, London, Wiley.

9. Pearson, J., Ever Deeper Research and Innovation Governance? Assessing the Uptake of RRI in Member States' Research and Innovation Programmes, in: Gianni, R. et al., (eds.), 2019, Responsible Research and Innovation: From Concepts to Practices, Abingdon, Routledge.

10. Ribeiro, B. et al., 2017, A Mobilising Concept? Unpacking Academic Representations of Responsible Research and Innovation, Science and Engineering Ethics, Vol. 23, No. 1 .

11. Schomberg, R. von, Prospects for Technology Assessment in a Framework of Responsible Research and Innovation, in: Dusseldorp, M., Beecroft, R., (eds.), 2011, Technikfolgen abschätzen lehren: Bildungspotenziale transdisziplinärer Methoden, Wiesbaden, Vs Verlag.

12. Schomberg, R. von, A Vision of Responsible Research and Innovation, in: Owen, R., Heintz, M., Bessant, J., (eds.), 2013, Responsible Innovation, London, Wiley.

13. Stahl, B. C. et al., Responsible Research and Innovation in Information and Communication Technology: Identifying and Engaging with the Ethical Implications of ICTs, in: Owen, R. et al., (eds.), 2013, Responsible Innovation: Managing the Responsible Emergence of Science and Innovation in Society, London, Wiley.

14. Stilgoe, J. et al., 2013, Developing a Framework for Responsible Innovation, Research Policy, Vol. 42, No. 9.

15. Zwart, H. et al., 2014, Adapt or Perish? Assessing the Recent Shift in the European Research Funding Arena from 'ELSA' to 'RRI', Life Sciences, Society and Policy, Vol. 10, No. 11. 


\section{Legislative SOURCES}

1. Act 2014:LXXVI on scientific research, development and innovation (Hungary).

2. Act 2019:LXVIII on the amendment of the institutional and financial framework of research, development and innovation (Hungary).

3. Government Regulation 380/2014. (XII. 31.) (Hungary).

4. Government Decision 1481/2018 (X. 4.) (Hungary).

5. Government Regulation 344/2019 (XII. 23.) (Hungary).

6. Higher Education and Research Act 2017 (UK).

7. Resolution No. 926 of the National Assembly (Résolution de l'Assemblée nationale sur les sciences et le progrès dans la République) (France).

\section{INTERNET SOURCES}

1. German Citizen Science Platform, (https://www.buergerschaffenwissen.de/en).

2. Inzelt, A., Csonka, L., Responsible Research and Innovation in Hungary: Review of National Policies (ResAGoRa, 2013), (https://rritrends.res-agora.eu/uploads/10/ RRI\%20in\%20Hungary\%201st\%20Report_final.pdf).

3. Sciencewise (UK) (http://sciencewise.org.uk/).

4. Sciencewise (UK) Public Dialogue Guiding Principles, (http://sciencewise.org. uk/wp-content/uploads/2019/11/Guiding-Principles.pdf).

5. Sciencewise (UK) Public Dialogue Quality Framework, (http://sciencewise.org. uk/wp-content/uploads/2018/09/Sciencewise-Quality-in-Public-Dialogue-August-2018.pdf).

6. The concept of the Hungarian Academy of Sciences on the role of science in the reform of the national innovation system (2018), (https://mta.hu/data/dokumentumok/rendkivuli_kozgyules_20181206/20181206_MTA_RK_3_napirend_ Az\%20MTA\%20koncepcioja\%20a\%20tudomany\%20szerepere.pdf).

7. The Dutch RRI Platform, (https://www.nwo-mvi.nl/).

8. The French National Strategy on Science, technology and industrial culture, (https://www.enseignementsup-recherche.gouv.fr/cid113974/la-strategie-nationale-de-culture-scientifique-technique-et-industrielle.html).

9. The German high-tech strategy (1), (https://www.hightech-strategie.de/en/index. html).

10. The German high-tech strategy (2), (https://www.bmbf.de/upload_filestore/pub/ Research_and_innovation_that_benefit_the_people.pdf).

11. The strategy of the German Citizen Science Platform, (https://www.buergerschaffenwissen.de/sites/default/files/grid/2017/11/21/gewiss_cs_strategy_englisch_0. pdf (Germany).

12. The UKRI's public engagement framework (1), (https://www.ukri.org/public-engagement/research-council-partners-and-public-engagement-with-research/).

13. The UKRI's public engagement framework (2), (https://www.ukri.org/files/per/ ukri-vision-for-public-engagement-pdf/). 
14. The 2013-2020 Hungarian RDI strategy, (https://nkfih.gov.hu/hivatalrol/strategia-alkotas/nemzeti-kfi-strategia).

15. The 2014 national smart specialization strategy (Hungary), (https://nkfih.gov.hu/ hivatalrol/nemzeti-intelligens/nemzeti-intelligens).

16. The 2016 Peer-review Report on the Hungarian RDI System, (https://nkfih.gov. hu/hivatalrol/szakpolitika-strategia/kfi-helyzetelemzes).

17. The 2020 French National Research Strategy, (https://cache.media.enseignementsup-recherche.gouv.fr/file/Strategie_Recherche/26/9/strategie_nationale_recherche_397269.pdf).

18. Wissenschaft im Dialog (WiD) GmbH, (https://www.wissenschaft-im-dialog. de/en).

\section{ODGOVORNO ISTRAŽIVANJE I INOVACIJE (RRI) \\ U MAĐARSKOJ: ZAPADNI MODEL, ISTOČNI NELIBERALNI REŽIM I SLUČAJ ODLOŽENE INSTITUCIONALNE ADAPTACIJE}

Márton Varju

\section{APSTRAKT}

Odgovorno istraživanje i inovacije (RRI) predstavljaju način upravljanja istraživanjem, razvojem i inovacijama (RDI) koji se razvio prvenstveno $u$ evropskim državama sa tradicijom i/ili kulturom zajedničkog i savetodavnog upravljanja tehnologijom. Pretpostavlja postojanje otvorenih, transparentnih i pristupačnih procesa donošenja politika i kulture odgovornosti u vladinom i u privatnom domenu. U Mađarskoj, gde bi RDI trebalo da bude ključ ekonomske konkurentnosti, RRI nikada nije zaživeo. Proučavanjem regulative mađarskog RDI sistema, postaje jasno da postoji značajan stepen institucionalne nepodudarnosti sa rešenjima koja RRI promoviše. Štaviše, vladajuća većina i trenutni model kreiranja politike i upravljanja sprečavaju ili namerno isključuju primenu RRI-ja.

Ključne reči: RRI, odgovorno istraživanje i inovacije, sistemi istraživanja i inovacija, institucionalna adaptacija, neliberalna demokratija, neoveberijanska država, Mađarska.

Article History:

Received: 18 March 2021

Accepted: 11 June 2021 